\title{
EFFECT OF TEMPERATURE OF THERMOMECHANICAL TREATMENT ON QUALITY OF DISSIMILAR METAL JOINTS
}

\author{
L.Yu. DEMIDENKO, N.A. ONATSKAYA and V.D. POLOVINKA \\ Institute of Pulse Processes and Technologies, NASU \\ 43a Oktyabrsky Ave., 54018, Nikolaev, Ukraine. E-mail:iipt@iipt.com.ua
}

\begin{abstract}
At present time, pressure welding methods acquire more and more distribution for quality joining of dissimilar metals. The Institute of Pulse Processes and Technologies of the NAS of Ukraine has developed a new method of welding of materials in solid state using current pulses. In essence, it lies in the fact that metals being welded at ambient temperature are pressure contracted and specific amount of current pulses of amplitude density not less than $1.2 \cdot 10^{9} \mathrm{~A} / \mathrm{m}^{2}$ and duration not less than $2 \cdot 10^{-4} \mathrm{~s}$ are passed through deformation zone for intensification of plastic deformation at stage of physical contact formation. At that mutual deformation of surface projection provides for sufficiently tight contact of surfaces being welded and allows for their isolating from ambient environment. A welded joint is formed at further heating by type of diffusion one without application of special shield of the surfaces from oxidation. Aim of present work is an investigation of effect of temperature of thermomechanical treatment on quality of joints in welding of dissimilar metals in solid state using current pulses of large density. Such research methods as mechanical shearing tests, optical metallography and micro X-ray spectral analysis were used at that. It was determined as the result of experiments that $800{ }^{\circ} \mathrm{C}$ temperature is the most favorable for providing a quality steel 20 plus copper M1 welded joint, since at that no discontinuities are present in joint zone and clearly expressed initial structure is preserved in metal itself. 9 Ref., 3 Tables, 5 Figures.
\end{abstract}

$\boldsymbol{K} \boldsymbol{e} \boldsymbol{y} \boldsymbol{w} \boldsymbol{O} \boldsymbol{r} \boldsymbol{d} \boldsymbol{s}:$ welded joints of dissimilar metals, temperature of thermomechanical treatment, current pulses of large density, self-sealing of inter-contact zone, metallographic investigations, mechanical shearing tests

Application of metals and alloys dissimilar on their properties is typical for manufacture of welded joints in current commercial production $[1,2]$. This allows for using specific properties of each of them in full extent, reducing consumption of expensive and rare metals, producing of parts with high service properties and reducing their weight. In this connection, development of new, efficient and low-power consuming technological processes for producing of quality welded joints from dissimilar metals is relevant.

The Institute of Pulse Processes and Technologies (IPPT) of the NAS of Ukraine developed a new method of welding of metals in solid state using current pulses [3]. It is a variant of pressure welding with preheating.

In essence, it lies in the fact that metals being welded at ambient temperature are pressure contracted and specific amount of current pulses of amplitude density not less than $1.2 \cdot 10^{9} \mathrm{~A} / \mathrm{m}^{2}$ and duration not less than $2 \cdot 10^{-4} \mathrm{~s}$ are passed through deformation zone for intensification of plastic deformation at stage of physical contact formation. At that mutual deformation of surface projection provides for sufficiently tight contact of surfaces being welded and allows their isolating

(C) L.Yu. DEMIDENKO, N.A. ONATSKAYA and V.D. POLOVINKA, 2014 from ambient environment. A welded joint is formed at further heating without application of special shield of the surfaces from oxidation [4].

Steel 20 and copper M1 were selected for welding of dissimilar metals using proposed method. First of all, they are widely used in manufacture of technical parts in electrical technologies, transport, machine building and, secondly, they have significant differences in their physical-mechanical properties and crystallographic characteristics. Mutual solubility of these metals is relatively small and depends on temperature [5], therefore it was relevant to investigate their effect on quality of produced welded joints.

Aim of present work is an investigation of effect of temperature of thermomechanical treatment (TMT) on quality of joints in welding of dissimilar metals in solid state using current pulses of large density.

Materials and experiment procedure. Rectangular plates of $170 \mathrm{~mm}$ length, $12 \mathrm{~mm}$ width and $2.5 \mathrm{~mm}$ thickness were used as mock-up specimens for welding of dissimilar metals using current pulses of large density, at that zone of welding with length $l \approx 22 \mathrm{~mm}$ were taken in the middle of specimen (Figure 1).

Mechanical preparation of plate surfaces was carried out immediately before welding. It lied in their grinding up to combs height (microirregularities) $H_{0}=5-6 \mu \mathrm{m}$. Then, the plate surfaces were degreased by acetone. Plastic defor- 


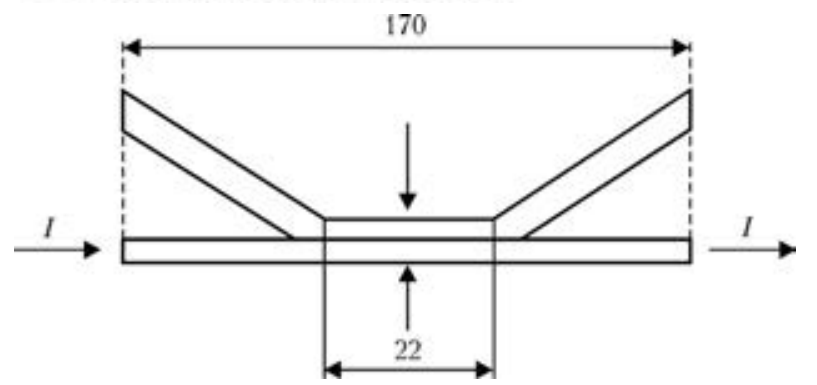

Figure 1. Scheme of contraction of specimens for treatment by current pulses

mation of microprojections over contact surfaces was carried out by pressing of the specimens at ambient (room) temperature in special device at calculation nominal pressure equal $50 \mathrm{MPa}$. Pulse current treatment of contact zone of pressed plates was performed by means of current passing along one steel plate. Parameters of pulse current was the same as in work [4], namely, amplitude of current density $J=1.85 \cdot 10^{9} \mathrm{~A} / \mathrm{m}^{2}$, pulse duration (attenuating sine wave) $\tau \approx 3 \cdot 10^{-4} \mathrm{~s}$, number of pulses $N=90$ and pulse sequence frequency $0.5 \mathrm{~Hz}$.

Pulse-treated specimens together with device were set in a chamber electric furnace for further heating.

Welded joints in order to determine the effect of TMT temperature on their quality were heated in the furnace to welding temperature, which according to [6] was selected in $0.5-0.7$ range from melting temperature, i.e. at 750, 800 and $850{ }^{\circ} \mathrm{C}$ and holding at indicated temperature during $20 \mathrm{~min}$. At least three specimens are necessary for each temperature level.

Quality of the welded joints were estimated using the results of metallographic investigations and mechanical tests of templates, cut out from contact zone of welded specimens (see Figure 1). At that, each template was cut along the cross section. One part of the templates was used for metallographic investigations and another one for mechanical tests.

The microsections for metallographic investigations were taken normal to contact plane. Preparation of sections to investigations lied in

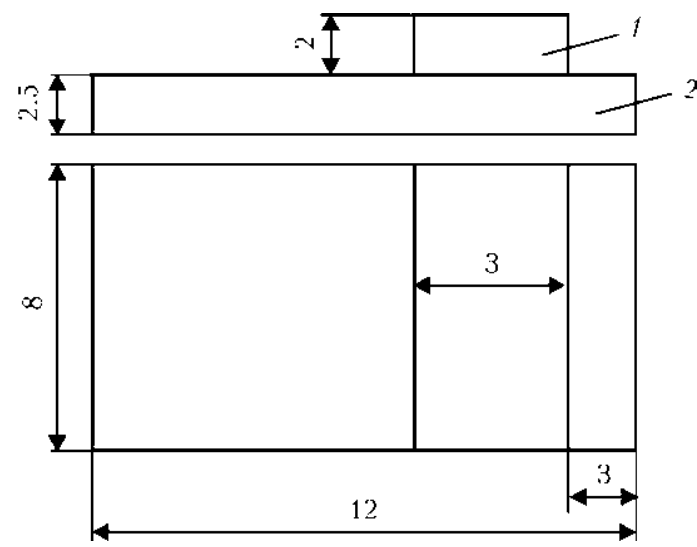

Figure 2. Scheme of specimen for shearing tests: 1 - copper plate section; 2 - steel plate mechanical grinding and further etching in $4 \%$ alcoholic nital [7].

Welded joint quality was preliminary estimated by condition of boundary along the joint line (by discontinuities presence). At that, estimation of boundary condition was carried out along its width, which is determined using metallographic microscope «Microtech» of MMO-1600 model at 400fold magnification. If discontinuities along the joint line are present, their measurement is performed at 1000-fold magnification in 100 points homogeneously distributed along the joint line. Fraction (in percent expression) of that or other values of boundary width along the joint line was calculated based on their results.

Distribution (diffusion) of elements was examined using a method of micro X-ray spectrum analysis in the cross section from base metal to joint line as well as along the joint line from copper side.

Mechanical strength tests (shearing tests) were carried out in accordance to GOST 1088585 for determination of stresses, promoting shearing deformation with fracture of welded joint along welding line. For this purpose, the specimens for investigations were produced from part of the templates (Figure 2).

The tests were carried out at laboratory bench, designed for investigation of static characteristics of materials and developed at IPPT using the device, scheme of which is given in Figure 3. This device allows for providing pure shearing stress in tested section of the specimen when applying tensile stresses $F_{\mathrm{s}}$ to guide plates. Loading of the specimens was carried out gradually with holding at each step during $3 \mathrm{~min}$.

Strength of the joints was estimated on shearing stresses $\tau_{\mathrm{sh}}=F_{\mathrm{sh}} / S_{\mathrm{sh}}$, where $F_{\mathrm{sh}}$ is the shearing force of tested section, $\mathrm{kN} ; S_{\mathrm{sh}}$ is the area of the section to be sheared, $\mathrm{mm}^{2}$.

Results of experiments and their discussion. Earlier the investigations were carried on study of change of surface projection under effect of pulse current using the scheme of current passing indicated above with the help of the Philips scanning electron microscope SEM 515 (Holland). Their results showed that treatment of preliminary compressed metal plates of steel $20+$ copper M1 by current pulses of large density promotes for significant deformation of their surface projection, as a consequence of which area of physical contact covering 60 to $80 \%$ of general contact area is formed [4]. Mutual deformation of surface projection if applicable to investigated welding method provides for sufficiently tight contact of surfaces being welded, that allows for their isolating from environment and creates the possibility of producing of welded joint without application of shielding medium at further heating. This fact was verified experimentally in the same work. 
Table 1. Results of mechanical shearing tests of templates of steel $20+$ copper M1 welded joints

\begin{tabular}{|c|c|c|}
\hline $\begin{array}{c}\text { Heat treatment } \\
\text { temperature } T,{ }^{\circ} \mathrm{C}\end{array}$ & $\begin{array}{c}\text { Shearing stress } \tau_{\text {sh }}, \\
\mathrm{MPa}\end{array}$ & $\begin{array}{c}\text { Relative shearing } \\
\text { stress } \bar{\tau}_{\mathrm{sh}}\end{array}$ \\
\hline 750 & $176.0 \pm 6.2$ & 0.96 \\
\hline 800 & $180.7 \pm 3.5$ & 0.98 \\
\hline 850 & $174.2 \pm 5.1$ & 0.95 \\
\hline
\end{tabular}

Rise of temperature at stage of volumetric interaction is necessary for artificial increase of ductility of welded metals and acceleration of diffusion processes. Besides, the heat treatment intensifies diffusible solution of hydrogen from near-surface metal in metal depth. As the result oxidized layer is diffused and does not play a role of barrier for emergence of dislocations in the joint zone. Rates of activation and setting of contact surfaces are increased at that, and development of interaction of metals being joined takes place in contact plane with formation of strong metallic bonds as well as in volume of contact zone.

Table 1 gives the averaged results of measurement of shearing stresses of welded joints produced at different temperatures.

Comparison of strength of welded joints and base metal was carried out. For that, base metal specimen (copper in given case), which is similar to welded one (see Figure 2), was subjected to thermo-deformation impact, simulating welding conditions, and tested using the same procedure. Thus, relative shearing stress $\bar{\tau}_{\mathrm{sh}}$ was determined for all investigated welding temperatures as

$$
\bar{\tau}_{\mathrm{sh}}(T)=\tau_{\mathrm{sh}}(T) / \tau(T),
$$

where $\tau_{\mathrm{sh}}(T)$ is the shearing stress, received at welding temperature, $\mathrm{MPa} ; \tau(T)$ is the shearing strength of base metal after heat treatment on welding mode, MPa.

Table 1 provides for calculation values of relative value of shearing stress.

The results of mechanical tests determined that shearing strength of produced welded joints is changed in a narrow range from 174.2 to $180.7 \mathrm{MPa}$ at variation of welding temperature from 750 to $850{ }^{\circ} \mathrm{C}$, that corresponds to copper strength $0.95-0.98$.

Figure 4 shows the microstructures of zones of produced welded joints, and Table 2 gives the results of change of boundary width and its portion along the joint line. It can be seen from the Table that rise of TMT results in reduction of boundary width as well as increase of number of points along the joint line, in which its minimum width was registered. Thus, $8 \%$ of joint line examined length have defects of $0.5-1.0 \mu \mathrm{m}$ size at $750{ }^{\circ} \mathrm{C}$ THT temperature. The rest $92 \%$ have boundary width less than $0.5 \mu \mathrm{m}$. Defects of pore type and discontinuities in the joint zone are already absent at higher temperatures (800 and

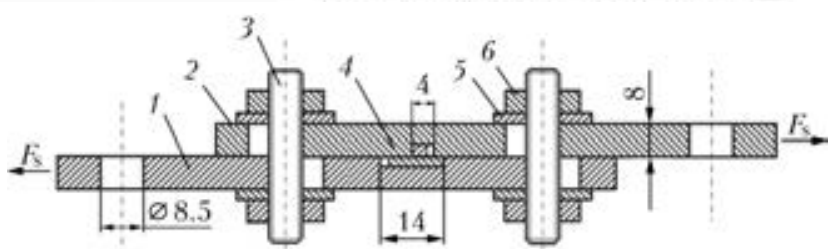

Figure 3. Scheme of device for shearing testing of specimens: 1, 2 - upper and lower guide plates, respectively; 3 pin; 4 - welded specimen; 5 - washer; 6 - nut

$850{ }^{\circ} \mathrm{C}$ ), and joint zone itself represents a grain boundary oriented in plate of initial contact $\left(\mathrm{Fi}^{-}\right.$ gure $4, b, c)$.

However, comparison of microstructures of produced welded joints shows that rise of TMT temperature to $850{ }^{\circ} \mathrm{C}$ results in grain growth in steel 20 in the joint zone as well as base metal (see Figure 4, c). This is undesirable moment, since it can promote reduction of welded joint strength characteristics.

It can be concluded based on the results of metallographic examinations that TMT temperature of $800^{\circ} \mathrm{C}$ is the most preferable for providing of quality welded joint from steel $20+$ copper M1. At that, no discontinuities are present in the joint zone, clearly expressed initial structure is preserved in the metal itself, and joint zone represents a grain boundary oriented in plane of initial contact.

Micro X-ray spectral analysis of nature of distribution of main elements in the cross section of central part of welded specimen, received after TMT at $800{ }^{\circ} \mathrm{C}$ during $20 \mathrm{~min}$, indicate that the composition is changed from $100 \% \mathrm{Fe}$ (or $\mathrm{Cu}$ ) to $100 \% \mathrm{Cu}$ (or Fe) (Figure 5) in near-contact zone of the joint. At that, penetration depth of copper (concentration up to $1 \%$ ) in steel 20 metal is around $15 \mu \mathrm{m}$ from joint line, and that for iron in copper makes approximately $13 \mu \mathrm{m}$. The results obtained can be completely agreed with current understanding that appearance of diffusion zones at joint boundary is typical for metals with limited mutual solubility [8]. Their formation is related with the fact that some amount of copper atoms penetrates (diffuse) in iron through interface as a result of specific solubility. Similarly, some amount of iron atoms diffuses in copper (Table 3).

The results, presented in Table 3 and Figure 5, show formation of solid solutions along the joint line and in cross section from the side of steel 20 as well

Table 2. Width of boundary and its percent content along joint line at different TMT temperatures

\begin{tabular}{|c|c|c|c||}
\hline \hline \multirow{2}{*}{$\begin{array}{c}\text { Heat treatment } \\
\text { temperature } T, \\
{ }^{\circ} \mathrm{C}\end{array}$} & 1.0 & $\sim 0.5$ & $<0.5$ \\
\cline { 2 - 4 } & 7 & 1 & 92 \\
\hline 750 & - & - & 100 \\
\hline 800 & - & - & 100 \\
\hline 850 & \multicolumn{3}{|c||}{} \\
\hline
\end{tabular}




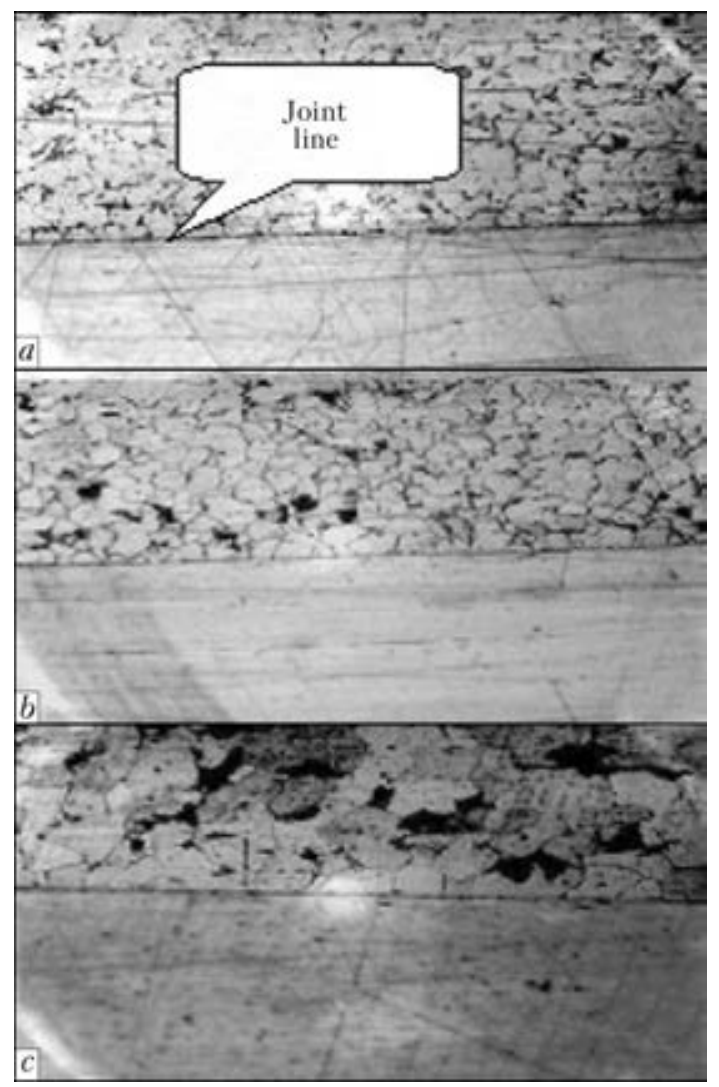

Figure 4. Microstructure $(\times 400)$ of zone of steel $20+$ copper M1 welded joints at $T=750(a), 800(b)$ and $850(c){ }^{\circ} \mathrm{C}$

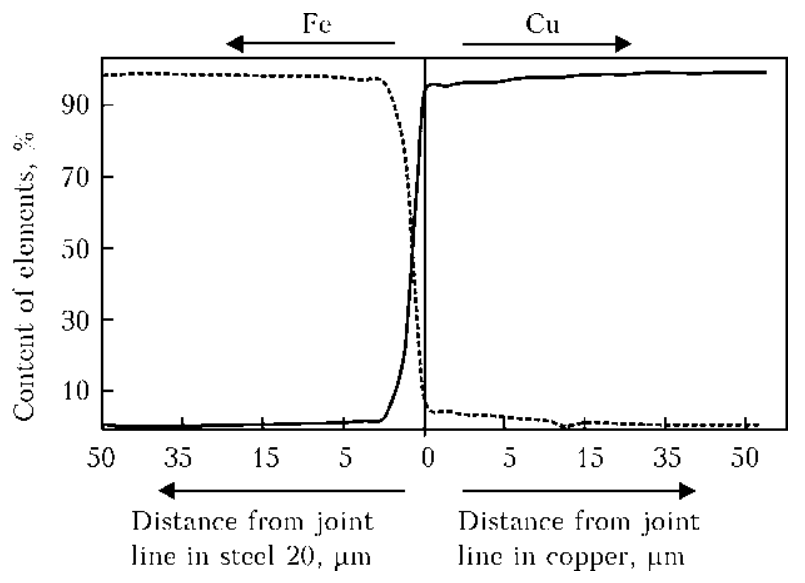

Figure 5. Nature of distribution of main elements in cross section of central part of steel $20+$ copper M1 welded joint after TMT at $T=800{ }^{\circ} \mathrm{C}$

as copper M1. This is an indication of processes of interatomic interaction of contact surfaces. At that, no phase formations, capable to result in welded joint embrittlement, were found.

Thus, welding method under investigation allows for producing of quality joints of steel $20+$ copper M1 at lower parameters of thermal deformation than in traditional diffusion welding. Besides, it can be done without application of special shield of surfaces being welded from oxidation, for example, vacuum processing or using controlled inert gas atmosphere. Isolation of welding zone from ambient media in welding using current pulses is provided as a result of self-sealing of
Table 3. Distribution of elements along joint line from copper side (in \%) at depth around $10 \mu \mathrm{m}$

\begin{tabular}{||c|c|c|c|c|c||}
\hline $\begin{array}{c}\text { Point } \\
\text { No. }\end{array}$ & $\mathrm{Cu}$ & $\mathrm{Fe}$ & $\mathrm{Cr}$ & $\mathrm{Mn}$ & $\mathrm{Ni}$ \\
\hline 1 & 99.60 & 0.38 & - & - & 0.02 \\
\hline 2 & 97.82 & 2.12 & 0.06 & - & - \\
\hline 3 & 96.84 & 2.74 & - & 0.11 & 0.32 \\
\hline 4 & 96.82 & 3.14 & - & 0.03 & 0.02 \\
\hline 5 & 97.22 & 2.45 & - & 0.13 & 0.20 \\
\hline 6 & 96.40 & 3.27 & 0.12 & 0.02 & 0.22 \\
\hline 7 & 96.85 & 3.09 & - & - & 0.07 \\
\hline 8 & 96.56 & 3.13 & 0.02 & 0.05 & 0.25 \\
\hline
\end{tabular}

inter-contact zone due to current-stimulated intensive plastic deformation of surface layers of metals being joined. Further heating of sealed space promotes formation of autovacuum, providing self-cleaning of surfaces from oxide films [9] and production of welded joint.

\section{Conclusions}

1. TMT temperature of $800{ }^{\circ} \mathrm{C}$ is the most favorable for welding of steel 20 and copper M1 dissimilar materials in solid state using current pulses, since no defects of discontinuity type are present in the joint zone, and clearly expressed initial structure is preserved in the metal itself.

2 . It is shown that zones of solid solutions are formed in cross section along the joint line from the side of steel 20 as well as copper M1. At that, no phase formations, capable to result in welded joint embrittlement, were found in these zones.

3. The results of mechanical tests indicate that produced welded joints have sufficiently high shearing strength comparable with base metal strength.

1. Middeldorf, K., von Hofe, D. (2008) Trends in joining technology. The Paton Welding J., 11, 33-39.

2. Reisgen, U., Stein, L., Steiners, M. (2010) StahlAluminium-Mischverbindungen: Schweissen oder Loeten? Die Kombination zweier etablierter Fuegetechnologien macht Unmoegliches moeglich. Schweissen und Schneiden, 62(5), 278-284.

3. Polovinka, V.D., Yurchenko, E.S., Vovchenko O.I. Method of diffusion welding of metals. Pat. 79181 Ukraine. Int. Cl. B23K $31 / 02$. Publ. 25.05.07.

4. Vovchenko, A.I., Demidenko, L.Yu., Onatskaya, N.A. (2011) Intensification of plastic deformation of metal surfaces under action of current pulses in pressure welding. Naukovi Notatky: Mizhvuz. Zbirnyk, 32, 63-68.

5. Kurt, A., Uygur, E., Mutlu, E. (2006) The effect of allotropic transformation temperature in diffusionwelded low-carbon steel and copper. Metallofiz. Nov. Tekhnol., 28(1), 39-52.

6. Kazakov, N.F. (1976) Diffusion welding of materials. Moscow: Mashinostroenie.

7. Kovalenko, V.S. (1973) Metallografic reagents, Moscow: Metallurgiva.

8. Karakozov, E.S. (1976) Joining of metals in solid phase. Moscow: Metallurgiya.

9. Paton, B.E., Medovar, B.I., Saenko, V.Ya. (1980) Spontaneous cleaning of metals from oxide films. Doklady AN SSSR, 159(1), 1117-1118. 